\title{
The Medicalization of Ethnicity in Vietnamese-American Women: Cosmetic Surgery and
} Hybridization

\author{
T. Thao Pham \\ California University of Pennsylvania \\ pham@calu.edu
}

DOI:10.5901/mjss.2014.v5n22p92

\begin{abstract}
Within the growing proliferation of the cosmetic procedures in the United States and worldwide, the alteration of ethnic features dominate surgeries chosen by Asians. This study surveys a group of Vietnamese women who have undergone ethno-altering cosmetic surgery in the United States and Vietnam. The study utilized semi-structured interviews and participant observations to elicit the following information from participants and their families, friends, and coworkers: a) How does the cosmetic procedures affect their acculturation to the United States? b) How have their experiences affected their cultural identity? c) How have they experienced their surgeries in relation to the presence of western technology, images, and culture? d) How have their experiences with their surgeries affected their relationships with friends, families, and coworkers? Fifteen women between the ages of twenty-five and sixty-five participated in this study. All subjects immigrated to the United States after reaching fifteen years of age with $58 \%$ had their procedures in Vietnam. Major findings include the claim by all subjects that the surgery was motivated by a pursuit of Asian standards of beauty, but with the specification by them typical of a hybrid mix of Western and Asian features.
\end{abstract}

Keywords: ethnic identity, cosmetic surgery, plastic surgery, Vietnamese women, acculturation

\section{Introduction}

The sense of beauty and the inclination for status and success may differ from one ethnic group to the next. However, standards for beauty and status for some minority groups mimic the prevalent features and characteristics of the dominant group (Sarwer, Grossbart, \& Didie, 2003; Slupchynskyj, 2005). The dominant group not only has the power in numbers, but it also has the power of influence. Taking on some of the influential characteristics may be one way minority groups can grasp some of the perceived power and status of the dominant group.

For several minority groups, ethno-altering of the facial features is one way to identify with the majority. Ethnoaltering or changing one's ethnic appearance has been made possible with the technological advances of surgery. Some social scientists see plastic surgery as a step towards a modern version of ethnic cleansing for people of color (Boras 2007; Slupchynskyj, 2005). About $45 \%$ of cosmetic surgery on Asian Americans consists of eyelid surgeries, while twenty percent involves having nose implants and nasal tip refinement (Kaw, 1993; Nguyen 2005; Xuvn 2013). For certain minority groups, such as Asian Americans, African-Americans, and Latin Americans, ethnicity is distinguished by facial characteristics, followed by language and culture (Rosenthal, 1987). In altering ethnic features, distinctions between ethnic groups can be less defined and more apt to fit the western ideal of beauty (Bulbeck, 1998). Looking different for certain groups is a mark of their ethnicity and minority status.

Recent studies have indicated a growing trend in cosmetic surgery in U.S. ethnic minorities with Asian Americans having the largest increase in cosmetic procedures between 2007-2008 and fueling a market that aim to reach $\$ 17.5$ billion by 2015 (American Society of Plastic Surgeons, 2013; Wimalawansa, McKnight, and Bullocks, 2009). The procedures for minority groups tend to be ethnically specific. Asians prefer blepharoplasty (eyelid surgery) and rhinoplasty (nose reshaping), while Latinos prefer breast and buttock augmentations.

Racial minorities often internalize the body images revered by the dominant culture's racial ideology. By revising their body parts, many Asian women are attempting to rid themselves of the effects of their internalized racism. These Asian women may consciously want plastic surgery to look beautiful, but their need to look more Anglo is an unconscious denouncement of their cultural identity (Kaw, 1993; Nguyen 2005). The results of the ethno-altering surgery have both advantages and 
disadvantages. Dubois (1993) contends that the emotional cost of assimilation outweighs the perceived benefits and may lead to more depression. Hence, looking less Asian can also improve their social status as racial minorities. Economic success implies easy assimilation into American society, while lack of success is looked upon as resisting acculturation (Dubois, 1993). Having the surgery represents a mark of status, where one is finally incorporated into the technological world of the dominant, white group.

\section{Method}

\section{Sampling}

A small, non-probability sample $(n=15)$ of Vietnamese women who have had ethno-altering cosmetic surgery participated in the study. The use of snowball sampling was used in finding participants with most participants acquired through friends, Vietnamese businesses, and various Vietnamese trade schools in the Houston and San Francisco. Participants met the following recruitment criteria: 1) a Vietnamese woman at least 18 years of age 2) having had ethno-altering cosmetic surgery 3) had the surgery in the U.S. or Vietnam 4) had the surgery with the past two years. The study utilized semi-structured interviews and participant observations to elicit the following information from participants and their families, friends, and coworkers: a) How does the cosmetic procedures affect their acculturation to the United States? b) How have their experiences affected their cultural identity? c) How have they experienced their surgeries in relation to the presence of western technology, images, and culture? d) How have their experiences with their surgeries affected their relationships with friends, families, and coworkers?

\section{Data Collection Methods}

Since little information or research has been implemented in studying the relationship between ethno- altering cosmetic surgery and acculturation, an exploratory, qualitative research design is the most appropriate for this study. A flexible method of interviewing would allow for examination of this issue, in which face-to-face, semi-structured interviews were used to guide questions as well as allow for exploration of important themes. With the difficulty of locating these subjects, phone interviews were also used to acquire subjects and data. The majority (14 out of 15) of the participants live in Houston, Texas for face-to-face interviews. Since one participant live in San Francisco, I conducted that interview by phone. All participants had agreed to have their interviews recorded by a digital voice recorder. No major costs in terms of special equipment or materials were needed.

Human subjects' approval was received prior to contacting subjects. Consent forms were given to prospective subjects to read and sign prior to the interviews. Confidentiality was the primary concern for some of the subjects. In many Vietnamese families, family secrets and struggles remain strictly within the family unit. Careful measures were used to ensure confidentiality for the subjects and their families. Although the interviews were conducted at the subjects' home, workplace, school, or businesses, the subjects set private areas aside for comfort and some degree of confidentiality. Accuracy was enhanced during the process of the study by keeping notes of the interviewing environment and recording both verbal and nonverbal interactions of the interviews. The interviews were transcribed from audiotapes and erased immediately after transcription.

While the interview schedule made it easier to gather large amount of information in a short period of time, it also had limitations. Although the interviews did not require translation since the researcher is fluent in Vietnamese, translation from English to Vietnamese may not be accurate due to certain Vietnamese expressions that do not have their equivalence in English and vice versa. In addition, the participants might not have understood the questions and might have provided vague, incomplete, or distorted responses for other reasons. The accuracy of the data is dependent upon the honesty of the participants' responses.

\section{Data Analysis}

Unstructured data gathered in this study was recorded and analyzed manually. Since some of the interviews were in Vietnamese, initial transcriptions were in its original language and translated into English afterwards. Data were compiled and compared for common themes and specific responses of interest. First I listed and clustered similar topics together, and then I formed them into columns. Columns consisted of major topics, unique topics, and leftovers. Data that did not match specific categories were collected and examined for other important themes related to the research. 


\section{Results}

The qualitative descriptions of these Vietnamese women who have undergone ethno-altering cosmetic surgery revealed complex motivations for having surgery. The findings supported the aim of the study by allowing these experiences to have a presence in the limited collection of literature about Vietnamese-American s. This study pointed to other areas of research concerning acculturation and racism. Past research on acculturation and racism did not explore the experiences of Vietnamese-American women in this capacity. Therefore, the findings supported the aim of the research by generating descriptions of the Vietnamese women's experiences and understanding of their ethno-altering cosmetic surgery.

\section{Participants}

The age range for this group of fifteen subjects was twenty-five to sixty-five years of age, and all fifteen subjects in this study immigrated to the United States after reaching fifteen years of age. Thus, all fifteen subjects spent their childhood and adolescent years in Vietnam, which also meant they were all first generation Vietnamese refugees. The time of immigration ranges from the first immigration wave of 1975 to the most recent immigration of 1997. Eleven out of fifteen lived in Houston, Texas, and one resided in the San Francisco area. Both areas have a high concentration of Vietnamese population.

United States citizenship was not a good measurement for national affiliation and cultural identity due to the variation in the time of immigration. Another reason was that all the subjects identified themselves as Vietnamese people with or without the United States citizenship. Two subjects out of fifteen believed that having U.S. citizenship meant being less Vietnamese. Those two participants felt that obtaining a United States citizenship meant betraying their affiliation with Vietnam and their ancestors. On the other hand, ten out of fifteen perceived U.S. citizen status as increasing resources, not as a change of national or cultural identity.

In terms of the socioeconomic background, the subjects ranged from working class to upper-middle class status. Five came from a working class background. Five out of the fifteen subjects fell in the middle class status, and two were classified in the upper-middle income bracket. The socioeconomic status of these women in Vietnam was difficult to measure as the earned income and time of immigration varied among the women. Interestingly, all fifteen subjects were educated in Vietnam, with the high school as the highest level of education completed. Below is brief information on some of the participants in the study. I have used pseudonyms and changed some background information to ensure confidentiality of the participants.

\section{Mau}

Mau, a thirty nine year old store clerk, gave the above statement about her motivation to alter her eyes and enhanced her looks, as well as improving her health. Mau immigrated to the United States with her family at the age of seventeen in 1975. She obtained her citizenship in 1983 and had her cosmetic surgery in 1984, less than a year after acquiring the American citizenship. When asked about short time span between two significant events, she remarked, "I wanted to do both at once: being an American and looking better."

\section{Hoa}

Hoa was a thirty-seven year old seamstress who came to the United States in 1985 at the age of twenty-five. She had her surgery two years prior to her resettlement in the United States. Hoa was considering applying for citizenship in the future. The need to prepare for the resettlement and acculturation process appeared to be the reason for her cosmetic surgery. She worked as a seamstress in a tailor shop nearby her residence and was married with three children. Hoa had plastic surgery on her eyes, nose, and chin. I wanted to look better. Bigger eyes are better with two folds instead of one. Besides, my original eyes reminded my mother of her hated father.

\section{Linh}

Linh was a forty-four year old housewife who immigrated to the United States in 1984 at the age of thirty. She obtained her citizenship in 1997 at thirty-seven years old. Her eyes were made larger with the double folds in 1982, also two years prior 
to her immigration. As with Hoa, acculturation played an important role in the decision to have surgery. However, Linh's altering of her eyes also impacted her relationship with her mother, who associated Linh's original eyes with the conflictual relationship with her mother's father.

\section{Dao}

Dao, a thirty-three year old hairstylist, wanted to fit in with her friends. Her motivation appeared to deal primarily with peer group relations, in which she wanted to join her friends and cooperate with them in the cosmetic surgery endeavors. She only had her eyes fixed but remarked how she regretted the surgery, which she had in Vietnam when she was twenty years old. She came to America in 1994 at the age of thirty and claimed how she did not want a citizenship here because she wanted to remain Vietnamese.

\section{Lan-Truc}

Lan-Truc was a twenty-seven year old nail technician who came to the United States in 1993 at the age of twenty-four.

She was not a citizen but would like to become one in the near future. She had her nose surgery when she was eighteen years old with her parents' permission. It also seemed to be the natural method to enhance her looks since so many members of her family endorsed cosmetic surgery.

\section{Khanh}

At forty-three years old, Khanh reflected her motivation to fit in with her friends and the community when she had her eyes altered at the age of twenty-six in 1980. Khanh came to America in 1990 when she was thirty-six and obtained her citizenship one year ago. She worked as an attendant for a dry cleaning store and was married with three sons. Khanh noted she felt so naive and young when she had her cosmetic surgery. During an interview, she claimed, "I became afraid after I had it done. I didn't think about it until after I came back to the doctor's office and saw blood on someone else's face." Khanh als she regretted the surgery:

\section{Hang}

Hang was twenty-four years old when she came to the United States in 1979 with her husband and their four children. She had her eyes and nose surgery in 1983, at the age of twenty-eight, and obtained her citizenship six months later. At fortythree years old, Hang worked as an assembly worker for a major computer corporation. She emphasized how the surgery made her feel better: "It was something I wanted before I came to America. To me, it was part of coming here and living here. " Hang perceived the surgery as part of the resettlement package and a new beginning for her family as they were impoverished in Vietnam.

\section{Thu-Thuy}

Thu-Thuy immigrated to America in 1997 with her husband and their twenty-year-old son. She was forty-five at the time of the interview and was working on her licensure as a manicurist. Although not yet a citizen, Thu-Thuy was looking forward to being a US citizen in the future. Thu-Thuy had her eyes altered in 1980 when she was twenty-six years old. Her motivation for the surgery was peer group relations: she saw all her friends with the ethno-altering surgery and wanted to join them. Thu-Thuy regretted her surgery and wished she never had it done.

\section{Phuong}

Phuong immigrated to the United States in 1975 with her husband and their three children. Phuong was twentyfive-years old when she resettled in America. Her husband died five years later in a car accident, leaving Phuong widowed but with a large sum of money from his life insurance. Phuong decided to go into real estate with the money and became successful. She had her eyes and nose altered in 1982 at the age of thirty-one and acquired her citizenship within a year of surgery. Her motivation for the surgery was to make herself more presentable and more marketable as a saleswoman and as an American. 


\section{Tien-Hanh}

Tien-Hanh was twenty-one years old when she had her nose surgery in Vietnam. With much distress and conflict with her family after the surgery, Tien-Hanh felt guilty for having the surgery without her family's permission. At the time of the interview, Tien-Hanh was working as a nail technician in salon owned by a family friend. She was twenty-five years old at the time of the interview. Tien-Hanh immigrated in 1997 and looked forward to becoming a citizen. For Tien-Hanh, the cosmetic result of the surgery pleased her, but she regretted defying her parents' objection to the surgery. She talked about the difficult period after the surgery involved family conflict, although her family eventually accepted her altering her face.

\section{Huong-An}

Huong-An was thirty-two when she had her cosmetic surgery in 1988, and the doctor she referred to was a well- known Vietnamese plasticsurgeon in the San Francisco area. Huong-An immigrated to the United States in 1985 by herself. Though she had a sister in Texas, Huong-An wanted to be on her own in California. She married within a year of her surgery and became a United States citizen in 1993. Although it was convenient for Huong-An to have her ethno-altering surgery, Huong-An also wanted to look better and to fit in more in the new country.

\section{Minh}

Minh had her eyes and nose surgery by an American doctor in 1990 at the age of thirty. Minh, who immigrated to the United States in 1975 at the age of fifteen, was more skeptical about the skills of Vietnamese doctors. Although she identified herself as Vietnamese, she perceived the American doctors as more knowledgeable. Minh attended one year of high school in America but dropped out and married at seventeen. Her cosmetic surgery was a celebration of her success as an entrepreneur with a chain of grocery stores. Minh associated the surgery with a mark of success and status.

\section{Findings of Acculturation}

Acculturation was a motive for the ethno-altering surgery with some participants. The findings also showed that having the surgery symbolized status. These findings supported past research on Asian-America $\mathrm{n}$ women and plastic surgery, in which status was a strong motivator for some women (Kaw, 1993; Cuong 2013). The Vietnamese women in this study associated the surgery with "making it" because the ethno-altering surgery was a luxury only the wealthy can afford.

Acculturation is a process where elements of both one's own culture and the new culture are accepted to suit one's resettlement needs. For many of these women, the ethno- altering surgery prepared them for different stages of the acculturation process. Seven out of the fifteen subjects interviewed had their surgeries in Vietnam. Two out of the seven women had their surgeries within a year of coming to the United States. Linh reported the relationship between immigrating to the United States and the cosmetic surgery, "A lot of people wanted to have the surgery in hopes of coming to America. They figured that it's cheaper to get it done in Vietnam, and it makes it easier to adjust to America. I was anticipating on coming to America and had mine done right before we left." Hoa, another participant, explained the need to blend in more by stating, "We've heard so much about American technology and wanted to catch up somehow. Surgery was one way." According to Linh, the cosmetic surgery helped her, and others like her, prepare for their initial adjustment in a new country. Tien-Hanh noted that some women do try to acculturate by having the surgery, "I do believe that some people do fix their noses very high and eyes very big to look Anglo. They do it so they can fit in more before they come to the United States. It's so unnatural. I wanted mine to fit my face."

For the five subjects who had their surgeries in the United States, their associations to the surgeries varied. Two out of those five women had the surgeries within a year of their citizenship. For Hang, the surgery was a kept promise made by her husband. Mau wanted the fat in her lids removed so she would not look so "sleepy." However, both women saw their surgery as one step further in resettling in America. Hang remarked on the timing of the surgery: "I had it done right before I got my citizenship, and it felt right. They go together. I was promised this before coming here so having it made it complete." The surgery and the citizenship were one package. Phuong altered her looks in order to feel more competitive in the American market. Minh celebrated her business success with her surgery, which represented status for her. Huong-An wanted the surgery in Vietnam but eventually had it done in the United States. 


\section{Findings of Standards of Beauty}

The standards of beauty reported by the subjects were labeled by them as Asian but specific features mentioned as ideal were western. All research participants immigrated to the United States after reaching fifteen years of age with $58 \%$ had their procedures in Vietnam. Major findings include the claim by the participants that the surgery was motivated by a pursuit of Asian standards of beauty, but with the specification by them typical of a hybrid mix of Western and Asian features.

The findings show that all the participants in this study had the ethno-altering cosmetic surgery because they wanted to look more beautiful. Vietnamese culture regards beauty as an important virtue in women. The four virtues for ideal feminine beauty are (a) to be a good housewife (b) to have a beautiful appearance (c) to speak well and softly (d) to be of good character (Kibria, 1993). Looking beautiful, for the participants in this study, is part of being a woman. To not want it is abnormal.

The main motivation for all fifteen subjects interviewed for this study was beauty as the primary reason for the cosmetic surgery. As Minh stated, "Women need to be beautiful. If their noses are flat and eyes are small, they should get it fixed. Women should be beautiful, and everyone wants beautiful things." The standards of beauty for all fifteen women were similar with regard to high noses and bigger eyes with double creases, not just one fold. Hoa described the need for bigger eyes: "The eyes are the windows to the soul. That's why we have to keep it open and big like the people on TV. " Another participant, Khanh, explained her reasoning for the popular ethno-altering surgery in the Vietnamese community in the United States and in Vietnam: "We want to fix it to enhance our Vietnamese features and to make it look natural. We can't look natural if we were to look Caucasian, " Huong-An noted, "You can't have it too high; then you look white. You can't look too whit e."

On the other hand, four out of the fifteen subjects thought that many other Vietnamese women change their looks to have more westernized features. Thu-Thuy commented on the need to look more Anglo: "Asian women having surgery to look more Anglo because they see the beauty of western features, and they also want that because there are so many magazines and beautiful American women on television." Accordingly, Huong Linh denied having her surgery to look more Anglo but attributed it to others:

"There are people who want to look more Anglo. That I have seen, but not for me. I can fix my own features, but I still can't change to look white. No matter how you fix it. The Americans know that you're Vietnamese. You can change all you want, but you'll still be Vietnamese, although some people do want to look more American and they change to look that way. I think you

can't change your ethnicity, but some people try to with surgery. I didn't. I just want to enhance what I have."

Nevertheless, all fifteen subjects admitted to wanting to look as if they were mixed with another race. The ideal result from surgery was for it to look natural without the Vietnamese features of a flat nose and small eyes. All fifteen subjects esteemed looking "mixed" with another race. Tien- Hanh stressed the ideal of the surgery was to look more mixed and not white, "We don't want to look white--just more mixed. We want to enhance our Vietnamese features. My friend actually looked Japanese when she had hers done. I just wanted to look like the way she had hers but to enhance my own features." Hoa summarized her friends' reactions after the surgery: "It looked so good that everyone thought I was mixed with Indian blood!"

All fifteen subjects ascribed successful and satisfying surgery to luck and the skills of their doctors. Mau described her experience of the surgery: "To get away from the surgery without harm and looking decent is luck. Some people are not that lucky. I recommend going to surgery in the morning when the doctors are alert. " Hoa described her doctor as "unique with a keen eye for beauty. He was careful and knew what he was doing." Minh, who did not trust Vietnamese doctors, went to an American doctor because "they're more professional and less likely to mess up."

The subjects who regretted their surgeries talked about how they would rather have their natural features back because the original features matched better with their facial structures. Three out of fifteen subjects regretted their surgeries, as in Thu-Thuy's remark, "I had small eyes with drooping lids, but I'd rather have that now because they match my face more."

\section{Findings of Family Relations}

An unforeseen effect of the ethno-altering surgery is on the family and community. Family relations were affected by the surgeries for many participants, with Confucian values and implications being one source of conflict around the surgery. 
The majority of the participants (60\%) spoke of shame and guilt for going against the Confucian principle of filial piety and dishonoring their family honor by altering their inherited facial features. Several women saw improvement in their family relations after the surgery. They believe that changing their facial features have improved their circumstances and fate.

The Vietnamese family usually consists of the nuclear family along with extended family members. The fifteen participants interviewed in this study all ranked their families as the most significant relationships in their lives. Nine out of fifteen participants reported that their surgeries affected their families. Five out of those nine participants had conflicts with their family members regarding the surgery. Mau talked about the surgery causing some friction between her and her mother:

"I didn't tell my parents. My husband knew about it. His family had their noses done. I didn't want my mother to know. She didn't need to know. When she found out, I felt guilty as if I took something away from her."

Thu-Thuy experienced the conflict with her husband and her shame for dismantling a filial piety, "My husband couldn't understand why I wanted to change what my parents have given me. I felt ashamed." Khanh reflected on how family was against her surgery for it went against their beliefs and culture:

"My family did not know about the surgery until afterwards. My mother was so upset. She said it was unnatural. They were something God had given to me and my parents have given to me. I shouldn't have changed it. Vietnamese custom dictated it. I wanted to fix my nose, too. But I went to a psychic who told me not to do it. He was upset at my eye surgery and said that I had tampered with fate. Fixing the nose would only make my bad luck worse."

Linh, however, had mixed results in her family. Her surgery cause some marital conflict with her husband as she described her interaction with her husband:

"He was against it [surgery]. I think it's because he didn't want other men to look at me. Men are selfish in that way. He told me not to change what my parents and God had given me. According to him, the surgery was going against fate and a need to compete with others. I disagreed. After I had the surgery, he liked the results. You see? Beauty is a way to keep the happiness in the family. Men look at pretty women all the time. It's a way to keep your husband."

On the other hand, Linh's relationship with her mother changed for the better:

"This surgery made me look different. I had my grandfather's eyes. They were very small, and my mother was not getting along with him. It was difficult for me because my eyes reminded her of my grandfather. After the surgery, my eyes were bigger and much different. They didn't look like my grandfather' s eyes anymore. My mother didn't feel as cold to me as she did before the surgery."

Linh altered her eyes, and according to a common Vietnamese belief, her fate. Ironically, her relationship with her mother improved as a result of altering of the "fate" on her face. Another participant, Khanh, went to a Vietnamese psychic after her mother became furious that she had her eyes altered. Khanh related her experience:

"My mother was so upset that I had changed something that was natural, that God gave me, and my parents, too. Vietnamese custom stated to keep things natural. But I wanted to fix my nose also. So I went to a psychic who told me not to do it. He was also upset at my eye surgery and said I had destroyed"

Contrary to Khanh's experience, four of the fifteen participants had positive relationships with their family before and after the surgery. Three women felt closer to their families, some whose members had already had cosmetic surgeries. LanTrue shared her newfound closeness with her family members:

"I never knew how it would affect my relationships with my mother and my brother. I guess I always felt left out. They both had theirs fix years before I had mine. I didn't expect something like this to bring us together. Especially something you have to fix! [giggled]"

Huong-An grew closer to her husband, who kept his promise to pay for her cosmetic surgery. In Huong-An's words, "It was one of the few promises my husband kept, and it made all the difference."

\section{Discussion}

Ethno-altering cosmetic surgery may be one derivative of Vietnam's long struggle against colonization and acculturation. With its western origin and influence, ethno-altering cosmetic surgery seems popular with several generations of Vietnamese-Americans. Vietnamese women have altered their faces in the United States and in Vietnam as it is cheaper and more discrete. Vietnamese doctors, trained overseas in the US and Europe, bring western technology and culture back to Vietnam (Cuong 2013; Brown 1970). The circulation of techniques, technology, and images has made cosmetic surgery 
a pinnacle of medical tourism and globalization. In fact, Vietnamese women are altering their faces not only in the United States but also in Vietnam. Vietnamese doctors, trained overseas in the United States and Europe, bring western technology and culture back to Vietnam. Although cosmetic surgery usually attracts women, some advertisements in Vietnamese magazines and newspapers also include men. The surgery advertisements focus mainly on raising nose bridges and cutting folds into the eyelids (Boras, 2007; Kaw, 1993; Wimalawansa, McKnight, and Bullocks, 2009). The advertised features are ethnically specific, yet the reasons for the increasing percentage of Vietnamese women, as well as a handful of men, choosing such surgery need further exploration. Although a certain number of Vietnamese men had these surgeries, this research focuses on women and their understanding of their cosmetic surgeries.

Wanting to look mixed supported the historical experience of Vietnamese people in the literature review. Vietnamese identity involves history, and Vietnamese history consists of continuous colonization and domination by foreign powers. The desire to look mixed is part of a Vietnamese identity, which incorporates the oppressive history of its people. In fact, this research illuminates the image of being "mixed" with another race was the look preferred by all participants. The participants perceive looking stereotypically Vietnamese as less attractive than looking mixed. According to the results, the ideal standard of beauty for these Vietnamese women consists of a blending of western features with a Vietnamese face.

Interestingly, the findings supported the notion that imported western images affected Vietnamese women's view of themselves and what they considered beautiful. The presence of media images on television and in magazines skews the standard of beauty toward to Anglo features. Some participants alluded to the effects of western images on the standards of beauty in Vietnamese women. They denied being influenced themselves by the western standard of beauty, but projected such standards onto others. Projection, a defense mechanism, refers to the process of attributing unwanted or bad feelings or thoughts of one's own to others.

The standards of beauty for all the participants reveal a desire for Anglo features. Eighty percent of the research participants claim that eyelid surgery changes their "sleepy eyes" to a more "awakened look, "which gives them more control of their lives. The "sleepy eye, " a term used to classify Asian eyes, condenses the images of passive, docile, slow-witted, and unemotional Asian women. Movies often depict these sleepy eyed beauties as objects of desire that are childlike, submissive, silent, and eager for sex (Hagedorn, 1994). The increasing number of facial surgeries on Asian women may result from a reaction against the association of negative stereotypes with their Asian features (Nguyen 2005). To combat some of the depression and isolation stemming from being and looking different, this study claims that plastic surgery has helped many Asian women look less stereotypically Asian.

Although this study focuses on some aspects of racism in the surgery, these experiences of acculturation are specific to the first generation Vietnamese-American women. They also bear witnessed to the war that ended the colonization of Vietnam and a long aftermath of resettlement and confusion. I would go one step further and argue that Vietnamese people have historically use acculturation as means of surviving the continuous presence of foreign domination. Vietnamese people use acculturation as a cultural coping mechanism. The findings also speak to the resettlement literature. A couple participants stress the need to remain Vietnamese by not wanting an American citizenship. The resettlement literature discusses how being a Vietnamese refugee means having to leave the ancestor's land and be separated from the family, the history, and culture. It comes with a feeling of shame, of not living up to one's Confucian obligation of continuing ancestral and familial traditions. A couple participants feel that obtaining a United States citizenship meant betraying their affiliation with Vietnam and their ancestors. On the other hand, a couple of the participants view the ethno-altering surgery as a symbolic of their acculturation. They altered their looks around the time that they acquired their United States citizenship. They viewed the citizenship and the surgery as one package, a package of acculturation and of their new lives in the United States.

Studies have found that Vietnamese women acculturate differently from Vietnamese men (DuongTran, 1996; Kibria, 1993; Matsuoka, 1993). The resettling in the United States provides new opportunities for both Vietnamese men and women. Vietnamese women, however, are often caught between their new access to resources in the United States and their traditional role in the family (Kibria, 1993). They struggle to balance the two conflicting demands of economic survival in the new country and maintenance of their familial expectations. Matsuoka (1993) notes that women are affected most by changes in family and community functioning because they lose their networks and social supports and feel estranged from the new social processes and expectations of roles and behaviors in the United States. One study found that feelings of isolation and depression are more prevalent in Vietnamese women than men (Matsuoka, 1993). Although depression is common in this population, a strong desire and willingness to learn about and adapt to life in the United States can balance depression (Haines, 1989). 
An unforeseen effect of the ethno-altering surgery is on the family and community. Many Asian families, especially Vietnamese families, live under the Confucian ideal of filial piety, which holds children eternally indebted to their parents (Ebrey, 1993; Jamieson, 1995). To cut, alter, or remove any part of the body is a crime against one's parents, as well as the heavens (Ebrey, 1993). Asian children learn from a very young age that their bodies are gifts from the heavens and their parents and ancestors; to intentionally change any part of the body means rejecting the family. Kaw (1993) contends that cosmetic surgery can further alienate people from family and their cultural identity.

Vietnamese women, who have had traditional roles in the families, find the new culture and economic opportunities confusing. They are often caught between taking advantage of more economic opportunities and keeping their traditional roles. Most Vietnamese women have been reared with Confucian ideology in which men dominate women (Kibria, 1993). A Vietnamese woman often marries young and takes on a subservient role in her in-laws' household. She has little domestic status until she produces a son. Traditional Vietnamese values dictate that a woman has three submissions: to obey her father, to obey her husband, and to obey her eldest son (Kibria, 1993). The need for Vietnamese women to work in the United States, which gives them more authority at home, causes problems for the family. Many husbands cannot understand why their wives are not living up to traditional expectations. On the other hand, the wives struggle with adapting to their new freedom while trying to maintain their traditional role at home (Kibria, 1993). One important virtue of an ideal Vietnamese woman is being a good housewife, which means partially means being able to keep the family together. Some of the participants believed that having the surgery help keep the family together. Looking beautiful would prevent the husband from running off with another woman. In this respect, the surgery was working with the Confucian ideal of the perfect woman.

Many Asian families, especially Vietnamese families, live under the Confucian ideal of filial piety, which holds children eternally indebted to their parents. To cut, alter, or remove any part of the body is a crime against one's parents, as well as the heavens. Findings for this study support other research on Vietnamese cultural identity (DuongTran 1996; Kibria 1993; Matsuoka, 1993; Nguyen 2005). The distinctive features of family life, particularly its cooperative and collective manifestations, remain a source of cultural pride and self- esteem. Some participants spoke of shame and guilt for going against the Confucian principle of filial piety. By altering their facial features, these participants had violated what their ancestors and the heavens gave them. Their regrets and sadness support past research on Asian women and plastic surgery, in which depression was common in many Asian women after having the plastic surgery (Kaw, 1993). Part of the depression came from the break in family relationships. The findings spoke to change in family relations caused by the participants' surgeries, some for the worse, and some for the better. Some participants experienced better relationships with their families as a result of the ethno- altering surgery. Although they still operate within Confucian context, the surgeries had helped family relations. The participants and their family members believed that having the ethno-altering surgery changed their fate, both the women's and their families' fates. The participants whose family relations were poor prior to the surgery experienced improvement in the relationships after undergoing the surgery. A change of fate was the explanation.

\section{Conclusion}

In summary, all participants in the study had ethno-altering cosmetic surgery because they wanted to look more beautiful, in which beauty is equated with success. The findings support the notion that imported western images affected Vietnamese women's view of themselves and what they considered beautiful. The presence of media images on television and in magazines skews the standard of beauty towards Anglo features. The participants altered their looks in order to change the stereotypical Vietnamese features of a flat nose and small "sleepy eyes" to more western features of a high nose bridge and the "awakened look." Despite wanting Anglo features, the participants did not want to look completely Caucasian but preferred the image of being "mixed" with another race, a hybridity of racial features. Moreover, having surgery also symbolizes status, which also has a socioeconomic impact. Nevertheless, altering one's look can affect family relations. Some families criticized altering inherited features as a insult to their family honor and the natural balance of face and body, while others saw improvement in familial relations after the surgery. Regardless of the outcome, the Vietnamese women in this study initially had ethno-altering cosmetic surgery to feel better about themselves and to attract positive interactions with others. With its western origin and influence, ethno altering cosmetic surgery seems popular with several generations of Vietnamese-Americans. Some people would go as far as ethno-altering cosmetic surgery to make assimilation easier. Many Vietnamese people, particularly women, have adopted to a western standard of beauty. The $\$ 17$ billion cosmetic surgery industry plays an active role in reproducing these cultural ideals and influences. Some Vietnamese women, as with many other Asian women, seek to acquire the ideal Western images under the knife of cosmetic surgery. 


\section{References}

American Society of Plastic Surgeons. (2013, February 1). 2012 Plastic Surgery Procedural Statistics Full Report. Retrieved December 13, 2013, from American Society of Plastic Surgeons: www.plasticsurgery.org

Boras, S. D. (2007). Cosmetic Body Alteration and the Hymenoplasty Procedure: the Intersection of Culture, Technological Embodiment, and the 'Plastic Body'. Saarbrücken, Germany: VDM Verlag Dr. Mueller e.K.

Boyle, C. (2012, April 30). Implant Scare at Tough Time for Cosmetic Surgery Industry. Retrieved from CNBC: http://www.cnbc.com/id/45924571//mplant_Scare_at_Tough_Time_for_Cosmetic_Surgery_Industry

Brown, L. (1970). Face the Future. North Dallas Plastic Surgery News, 20.

Bulbeck, C. (1998). Re-orienting western feminism: Women's diversity in a postcolonial world. Cambridge, MA: Harvard University Press.

Cuong, N. X. (2013, March 23). Vietnam Cosmetic Surgery--Asia Cosmetic Surgery. Retrieved January 12, 2014, from Tham My Saigon: http://www.thammysaigon.com/en/Index.aspx

Dubois, T. (1993). Construction construed: The representation of Southeast Asian refugees in Academic, popular and adolescent discourse. American Journal, 19(3), 1-25.

DuongTran, Q. (1996). Psychosocial correlates of depression in Vietnamese adolescents. Child and Adolescent Social Work Journal, 13(1), 41-50.

Ebrey, P. (1993). The inner quarters: Marriage and the lives of Chinese women in the Sung period. Berkeley: University of California Press.

Hagedorn, J. (1994, January/February). Asian women in film: No joy, no luck. Ms., pp. 74-79.

Haines, D. (1989). Refugees as immigrants: Cambodians, Laotians, and Vietnamese in America. Totowa, NJ: Rowman and Littlefield.

Jamieson, N. (1995). Understanding Vietnam. Berkeley: University of California Press.

Kaw, E. (1993). Medicalization of racial features: Asian American women and cosmetic surgery. Medical Anthropology Quarterly, 7(1), 74-89.

Kibria, N. (1993). Family tightrope: The changing lives of Vietnamese-Americans. Princeton, NJ: Princeton University Press. Matsuoka, J. (1993). Demographic characteristics as determinants in qualitative difference in the adjustment of Vietnamese refugees. Journal of Social Services, 17(3-4), 1-21.

Nguyen, K. (2005, November 14). More beautiful in any color. More nonwhite women are getting cosmetic surgery, raising questions of cultural ideals of beauty. Orange County Register. November 14, 2005. Available at:. Retrieved January 23, 2008, from Orange County Register: http://www.psp-interactive.com/issues/articles/2005-09_07.asp

Rosenthal, D. (1987). Ethnic identity development in adolescents. In J. S. Phinney, \& M. J. Rothermam, Chilidren's ethnic socialization: Pluralism and development (pp. 156-179). Newbury Park, CA: Sage.

Sarwer, D. B., Grossbart, T. A., \& Didie, E. R. (2003). Beauty and society. Semin Cutan Med Surg, 22, 79-92.

Slupchynskyj, O. (2005, September 7). Ethnic rhinoplasty. Retrieved from Plastic Surgery Products: Available at: http://www.psp-interactive.com/issues/articles/2005-09_07.asp

Wimalawansa, S., McKnight, A., \& Bullocks, J. M. (2009, August). Socioeconomic impact of ethnic cosmetic surgery: Trends and potential financial impact the African American, Asian American, Latin American, and Middle Eastern communities have on cosmetic surgery. Seminar on Plastic Surgery, 23(3), 159-162.

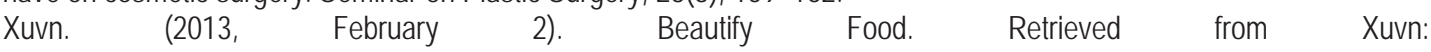
http://www.xuvn.com/beautifyfood/plastic\%20surgery/vietnamese_plastic_surgery.htm 